\title{
El lugar de la documentación tras la revolución de la información
}

\section{Francisco Javier García Marco}

Los últimos veinticinco años de las Ciencias de la Documentación han venido marcados por el impacto de la revolución de las tecnologías de la información. Dicha revolución, aunque ha seguido diferentes ritmos y cronologías según las peculiaridades condiciones de partida, ha seguido un curso común en la mayor parte de las organizaciones. Las fases de dicho curso son las siguientes:

- Una primera de sorpresa, desconcierto inicial y de cierto miedo al futuro.

- Una segunda de entrega a la tarea, de costoso y productivo aprendizaje de las posibilidades de las nuevas tecnologías.

- Una tercera más crítica de exigencia de adaptaciones específicas a las necesidades, objetivos, funciones, procesos, tareas y condiciones locales del sistema.

- Una cuarta en la que la tecnología se considera ya una precondición, deja de ser el centro de atención y se retoma una perspectiva global de la organización y de sus objetivos.

Efectivamente, la revolución telemática ha supuesto en nuestro campo un centraje, un anclaje y un reduccionismo — necesario a la par que brutal — del que en este momento estamos empezando a salir.

Ahora bien, después de la campaña es necesario revisar la situación en la que queda el campo de batalla. Creemos que algunos de los datos claves de la nueva situación — no por evidentes menos importantes— son los que siguen:

- La comunicación tecnológicamente mediada ocupa un lugar cada vez más importante en la actividad social, mientras que, gracias a las nuevas tecnologías, los mensajes documentados crecen de forma exponencial. Dicho crecimiento ha invadido el sistema social convirtiendo ala tecno-información es un proceso irreversible. 
- Se ha culminado el tránsito espectacular desde una sociedad en que la información era escasa y tenía un valor muy local para la mayor parte de la población a una sociedad sobre-informada y globalizada, aunque con grandes diferencias en el acceso a la información y sus tecnologías.

- La información y la documentación son actividades funcionales de las estructuras sociales donde se producen — comunidades de experiencia-, y requieren un análisis especializado y un conocimiento profundo de las arquitecturas cognitivas de dichas comunidades de experiencia.

Efectivamente, el acuerdo entre los especialistas que se dedican al mundo de la información y la documentación en estos enunciados es creciente, de tal manera que podrían considerarse algunas de las premisas fundamentales de la Ciencia de la Documentación en los albores del tercer milenio.

Sin embargo, dichas premisas, base de un cierto acuerdo epistemológico, contienen las semillas de un proceso de desagregación científica y profesional de la Ciencia de la Información Documental. Efectivamente, se aprecia un peligro creciente de que las 'documentaciones especializadas' sigan caminos separados a cargo de personas con adscripciones científicas y profesionales crecientemente divergentes.

La realidad de la especialización coincide además con un pulso de encuadre científico. Mientras que la propuesta de una gran Ciencia de la Documentación procedente del ámbito de la Documentación científica y, en menor medida, de la Archivística y la Biblioteconomía, de una Epistemología Social al decir de algunos de nuestros clásicos, ha pasado desapercibida fuera de las fronteras de las llamadas Ciencias de la Documentación, la propuesta de la Gestión del Conocimiento, nacida entre los gurús de la gestión empresarial y de las tecnologías de la información y apoyada en la hegemonía actual del paradigma cognitivo en las ciencias sociales y humanas, incide en buena en los mismos objetivos pero sin prácticamente ninguna referencia al campo documental.

¿Qué podemos hacer ante esta situación? En primer lugar, es necesario abrirnos al campo de la gestión del conocimiento, una suerte de ciencia cognitiva aplicada, y entrar en relación profunda con los investigadores y profesionales que se dedican a los diferentes aspectos de esa profesión. En segundo lugar, tenemos que encontrar en él un nicho diferenciado, una misión bien definida y una identidad clara. Encontrando nuestro lugar en el ámbito de las ciencias del conocimiento y de la gestión del conocimiento encontraremos también el territorio en el que relacionarnos en pie de igualdad con los profesionales e investigadores de otras áreas que se interesan por la gestión del conocimiento y trabajan en este campo. Ahora bien, ¡cuidado con las etiquetas! No son las marcas las que hacen una empresa líder, sino su lugar en el mercado y su cuenta de resultados. 